FORAMS 2006

\title{
The effects of heavy metal contamination on the foraminifera of a San Francisco Bay salt marsh
}

\author{
Michele Weber \& Lorraine R. Casazza \\ Museum of Paleontology and Department of Integrative Biology, \\ University of California, Berkeley, CA 94720, U.S.A. \\ mxweber@berkeley.edu
}

San Francisco Bay is the largest estuary system on the west coast of the Americas and it is ringed with salt marshes. As the human population has expanded and infringed on coastal areas, the marshes in the east bay were developed into housing projects, freeways and industrial buildings. At various times over the course of the last fifty years, the Richmond marsh was used as a waste area for a munitions factory and a sulfuric acid plant. The University of California, Berkeley, now owns the land. In early 2002 the marsh was tested for contamination resulting from previous industrial activity. The site was found to be very polluted. Lead, copper, arsenic, mercury, and selenium were elevated above the levels deemed acceptable by the standards of the Environmental Resources Management of the State of California. A remediation project was scheduled immediately that removed the top 4-6 feet of vegetation and mud and replaced it with clean sediment.

In the fall of 2002, prior to the start of the remediation project, we sampled the surface sediments on the marsh. We found the most polluted portion of the marsh to be acidic ( $\mathrm{pH}=1$ or so), discolored by the precipitation of Fe and devoid of foraminifera. The less polluted areas supported assemblages including Miliammina fusca, Trochammina inflata, Trochammina macrescens, Haplophragmoides wilberti and Haplophragmoides manilaensis. The distribution of foraminifera was patchy across the marsh and adjacent sample sites varied immensely. The percentage of deformed tests was around 5\% for most species. Multivariate statistical analysis revealed significant correlation between deformed foraminifera tests and heavy metal concentration. These data support the use of foraminifera as a potential indicator for metal pollution in estuarine environments. However in our samples, deformed tests were a small percentage of the total assemblage despite extremely elevated pollution levels; therefore, we advocate that these data be interpreted conservatively.

The remediation project commenced in 2003 and involved the destruction and removal of the contaminated surface sediments and associated vegetation. New mud was collected from a relatively clean site, spread over the remains 
of the marsh, and graded to approximate the elevation of the original site. We have been collecting surface sediment samples every one to two months since the start of the remediation project. Recolonization by local marsh foraminifera (predominantly $M$. fusca) was first observed in Fall 2005, three years after the remediation project began. The other foraminifera species present have been found near the tidal channels. As they are benthic, subtidal species, we presume they were lifted from the bay sediments and washed in by the tides. According to our observations, recolonization of the reconstituted marsh takes more than three years, but this is likely dependent on the development of the marsh flora that is normally utilized by the foraminifera. The plants have developed in patches separated by expanses of mud, which are subject to scour, currents, solar radiation and less cover than a natural, older marsh. As the plant and associated foraminiferal populations establish stable populations in the remediated marsh, a decrease in the percentage of deformed individuals could strengthen the case for using foraminifera as bioindicators for heavy metal contamination. 